\title{
A Strain of Pediococcus cerevisiae which requires Methicillin for Growth
}

\author{
By P. J. WHITE* \\ Twyford Laboratories, Twyford Abbey Road, London, N.W. Iо \\ (Accepted for publication 4 July 1967) \\ SUMMARY
}

By repeated subcultivation of the parent strain Pediococcus cerevisiae ATCC $808 \mathrm{I}$ in the presence of methicillin, a substrain $P$. cerevisiae $808 \mathrm{I}$ CRD was developed which grew only when the partly defined medium was supplemented with methicillin or certain other penicillins. The methicillindependent strain was not highly resistant to methicillin and grew only in the presence of a limited range of concentrations of it (about $\mathrm{IO}-300 \mu \mathrm{g} . / \mathrm{ml}$.). Even with an optimal growth concentration of methicillin (50-100 $\mu \mathrm{g} . / \mathrm{ml}$.), the dependent organisms grew less well than did the parent strain without methicillin and showed a longer lag period before growth became visible.

Although other derivatives of 6-aminopenicillanic acid (but not of 7-aminocephalosporanic acid) supported moderate growth of Pediococcus cerevisiae 808I CRD, none was as effective as methicillin, nor was there marked cross-resistance to any of these other derivatives. The more potent the penicillin as inhibitor of growth of the parent strain, the smaller was the optimal concentration needed to support growth of the dependent substrain. Several other antibiotics were ineffective as growth factors.

When methicillin was hydrolysed with acid, alkali or pencillinase, activity as a growth factor was lost. During growth of the parent strain and of the methicillin-dependent strain at $\mathrm{pH} 6.5$ material was produced in the medium which was able to destroy the antibiotic potency of methicillin or other penicillins. The substance was not an enzyme, and the presence of methicillin was not necessary to induce its formation by the parent strain.

The methicillin-dependent strain did not grow, with or without methicillin, when sodium acetate was omitted from the medium. No substance of known chemical structure was found which could replace acetate for growth. Pediococcus cerevisiae 808I CRD grew rapidly in the absence of both acetate and methicillin when the medium was supplemented with yeast extract. However, when acetate was present as well as yeast extract, methicillin again became necessary for growth of the dependent organisms.

\section{INTRODUCTION}

The occurrence of strains of bacteria which require streptomycin (or related drugs) for growth is well known, and the mechanisms responsible for dependence have been studied in some detail (Gorini \& Kataja, I964; Anderson, Gorini \& Breckenridge, I965). Such organisms possess a defective structural gene which can be phenotypically corrected by streptomycin owing to a misreading of the genetic code brought about by streptomycin. However, bacteria which are dependent for growth on drugs of other types have seldom been reported (Schnitzer \& Grunberg, 1957); cases of

* Present address: Department of Microbiology, The University, Western Bank, Sheffield, Io. 
penicillin-dependence are very rare. An instance of dependence on penicillin was described by Barber (1953a, b), who isolated colonies of staphylococci which grew only in the presence of benzylpenicillin; the products of penicillin hydrolysis with penicillinase or with acid did not support growth. The dependent strains were rather unstable and tended to revert to the ability to grow in the absence of benzylpenicillin. Jackson (1953) reported further work with the same strains. The penicillin-dependent organisms were much more sensitive to inhibition by oleic acid than were the parent organisms. When traces of oleic acid were removed from the medium (by extraction with ether) the organisms that previously were penicillin-dependent grew in the absence of penicillin.

The present work began with an attempt to develop a substrain of Pediococcus cerevisiae that would be resistant to benzylpenicillin. Methicillin (2, 6-dimethoxyphenylpenicillin; then called Celbenin) had been introduced (Rolinson et al. 1960) and it was of interest to attempt also to produce a methicillin-resistant substrain. Pediococcus cerevisiae was used because familiarity with this organism had already been gained during studies of its resistance to 5 -fluorouracil (White \& Nichol, 1963). In the attempts to develop resistance to benzylpenicillin little success was achieved, but with methicillin a substrain of moderate resistance was obtained which grew only in the presence of some methicillin. This substrain was called $P$. cerevisiae $808 \mathrm{I}$ CRD (Celbenin-resistant-dependent).

The development of this substrain, and some of its properties, are described in this paper. Preliminary reports of part of this work have already been given (White, 1962; Work, 1962).

\section{METHODS}

Organisms. Pediococcus cerevisiae (Leuconostoc citrovorum) ATCC 808I was maintained in tryptose glucose agar stab cultures which were incubated overnight at $37^{\circ}$. Stock cultures were transferred monthly and stored at $2^{\circ}$. Development of the methicillin-requiring substrain is described below in Results. Suspensions of organisms of this substrain in sterile horse serum were freeze-dried in ampoules. At about monthly intervals, a fresh ampoule was used to inoculate a tube of liquid partly defined medium (Io ml.) containing methicillin (I00 $\mu \mathrm{g} . / \mathrm{ml}$.). This culture was left to stand for $\mathrm{I}-2$ days at $37^{\circ} ; 0.1 \mathrm{ml}$. of the culture then was transferred to fresh medium (Io ml.) at intervals of $1-2$ days. Liquid cultures did not remain viable for much longer than a week, even when stored at $2^{\circ}$. Stab cultures in the partly defined medium containing methicillin (solidified with agar) remained viable for 2-3 weeks, when kept at $2^{\circ}$.

Staphylococcus aureus strain $\mathrm{JHM}$ and its cultivation were described by White \& Woods (1965).

Media. The partly defined medium (containing leucovorin) for Pediococcus cerevisiae was that used by White \& Nichol (1963). For growth of the methicillin-requiring organisms, the medium was supplemented (after autoclaving) with a sterile (filtered) solution of methicillin ( $100 \mu \mathrm{g} . / \mathrm{ml}$. final concentration). Tubes of sterile medium (Io ml.) supplemented with methicillin (for daily transfers of organisms) were kept at $2^{\circ}$. Similar medium solidified with $2 \%(\mathrm{w} / \mathrm{v})$ agar was used for stab cultures of $P$. cerevisiae 808I CRD.

The defined medium (containing leucovorin) was that of Sauberlich \& Baumann (I948) with uracil omitted. 
For counting of viable organisms, Difco CF assay medium (supplemented with leucovorin) was generally used, solidified with $\mathrm{I} \%(\mathrm{w} / \mathrm{v})$ agar. This medium was the same as the partly defined medium, except for the presence of uracil in the Difco medium. Sometimes the usual partly defined medium was used for counting.

For plate assays of penicillins the CYLG medium of Marshall \& Kelsey (I960) was used without glucose and $2 \%(w / v)$ agar added.

Glucose peptone water contained (g./1.): Oxoid peptone, 20; glucose, 20; sodium chloride, 5; adjusted to $\mathrm{pH} 7 \cdot 4$.

Conditions for growth experiments. Inocula were fresh overnight cultures in partly defined medium, diluted (sterile water) usually to a reading of 0.002 (in $6 \mathrm{~mm}$. diameter tubes) in the EEL photoelectric colorimeter (Evans Electroselenium Co. Ltd, Halstead, Essex) with neutral density filter (no. $\mathrm{I} \cdot 0)$ and with uninocculated medium for the zero setting. Inoculum ( $\left(0 . \mathrm{I} \mathrm{ml}\right.$.) was added to the medium $\left(4.9 \mathrm{ml}\right.$; ; autoclaved at $120^{\circ}$ for $7 \mathrm{~min}$.) in plugged tubes (150 $19 \mathrm{~mm}$.) which were set up in duplicate and incubated standing upright at $37^{\circ}$, usually in air.

Although cultures in test-tubes grew relatively rapidly and heavily, e.g. the parent strain in $20 \mathrm{hr}$ gave a turbidity reading of $\mathrm{I} \cdot 5-2 \cdot 0$, such a rate of growth was frequently not achieved when larger volumes of culture were grown in conical flasks. At least two factors seemed to be important, but were not examined in detail: the ratio of volume of medium to the surface area open to the air; and the period of autoclaving of the medium relative to its volume. A good rate of growth was obtained when cultures of $50 \mathrm{ml}$. or $150-200 \mathrm{ml}$. were grown in conical flasks of $100 \mathrm{ml}$. or $250 \mathrm{ml}$. capacity, respectively, standing at $37^{\circ}$. The medium was autoclaved at $120^{\circ}$ for $10 \mathrm{~min}$. and the inoculum was $0.1 \mathrm{ml}$. of a fresh overnight culture in partly defined medium. When samples for various measurements were removed during incubation of a culture, the medium was only gently stirred, just sufficiently to resuspend the organisms evenly, without causing much aeration of the medium.

For anaerobic growth, tubes were incubated upright in a glass McIntosh and Fildes jar in an atmosphere of hydrogen. The early stages of growth were observed through the sides of the jar, which was not opened until the end of an experiment. As an indicator of anaerobic conditions, a tube of glucose peptone water was used, coloured green by one drop of methylene blue ( $0.1 \%$ in ethanol). The green colour disappeared completely in about $20 \mathrm{hr}$ when conditions in a jar were anaerobic, and the colour reappeared in a minute or two when the jar was opened to the air.

Assessment of growth. Growth was roughly estimated by inspecting cultures at intervals over several days. When quantitative results were required, the turbidities of cultures were measured in an EEL colorimeter as described above. The relation between colorimeter reading and the dry wt organisms was linear from 0 to 3.0 on the colorimeter scale, and a reading of $\mathrm{I} \cdot 0$ was equivalent to $0.3 \mathrm{mg}$. dry wt organisms $/ \mathrm{ml}$. (for both strains).

Colony counts were made in various modifications of the partly defined medium solidified with $\mathrm{I} \%(\mathrm{w} / \mathrm{v})$ agar. A bottom layer of inoculated medium (IO ml.) was poured in a Petri dish at $43^{\circ}$. When this layer had set, an uninoculated covering layer ( $30 \mathrm{ml}$.) of the same medium, also at $43^{\circ}$, was poured. Plates were incubated at $37^{\circ}$ for 2-3 days until the colonies were large enough to be counted easily. Without a covering layer, colonies did not form evenly throughout the inoculated layer, no colonies being found nearer than about $2 \mathrm{~mm}$. to the surface open to the air. 
Pediococcus cerevisiae in liquid cultures in all the media grew as bunches made up of variable numbers of organisms ( $\mathrm{I}$ to about IOO). Consequently, a colony on a plate might have arisen from one organism or from several. The appearance (with the phase-contrast microscope with oil-immersion lens) of organisms from liquid cultures, and the range of sizes of the bunches were not noticeably altered when the composition of the medium was varied. The parent strain generally seemed to produce larger bunches of organisms than did the methicillin-dependent substrain. The number of bunches in a culture of either strain could readily be determined in a counting-chamber under the phase-contrast microscope with high-power lens, although the number of organisms making up a bunch could not be assessed. A fresh culture of either strain reading $\mathrm{I} \cdot \mathrm{O}$ on the EEL colorimeter scale gave a count of about $2 \times 10^{8}$ bunches of organisms $/ \mathrm{ml}$. in the chamber, and when plated in partly defined medium produced about $2 \times 10^{8}$ colonies $/ \mathrm{ml}$.

Growth of organisms at a constant $p H$ value. Partly defined medium ( $350 \mathrm{ml}$.) containing methicillin or broxil was inoculated with $\mathrm{I} \cdot 0 \mathrm{ml}$. of a fresh overnight culture of Pediococcus cerevisiae 808I CRD and incubated at $37^{\circ}$. The medium (in a special vessel) was maintained at $\mathrm{pH} 6.5$ during growth of the culture by the regulated addition of $2 \mathrm{~N}-\mathrm{NaOH}$ through a $\mathrm{pH}$ titrator apparatus (Type TTT I c; Radiometer, 72 Emdrupvej, Copenhagen NV, Denmark). The medium was gently stirred throughout the experiment with a small paddle fixed near the point of entry of the alkali.

Assay of penicillin. Medium CYLG (without glucose) containing $2 \%(w / v)$ agar was autoclaved at $120^{\circ}$ for $\mathrm{I} 5 \mathrm{~min}$. and then cooled to $43^{\circ}$. The molten medium (50 ml.) was inoculated with $0.5 \mathrm{ml}$. of a suspension of Staphylococcus aureus JHM in sterile water (about $10^{8}$ bunches of organisms $/ \mathrm{ml}$, from a fresh overnight slope culture on nutrient agar), and poured into a $15 \mathrm{~cm}$. diameter Petri dish. After the medium had set, holes were cut out with a cork borer $(8 \mathrm{~mm}$. diameter). Solutions for assay $(25-100 \mu \mathrm{l}$.) were pipetted into the holes, and the plates were immediately incubated at $37^{\circ}$. Next day the diameters of the zones of inhibition round the holes were measured, against the general background of growth. A plot of the square of this diameter against the $\log _{10}$ of the concentration of drug gave a straight line. The potencies of solutions under test were found by comparison with the line.

No change in concentration of methicillin occurred during the plate assay. Methicillin (100 $\mu \mathrm{g} . / \mathrm{ml}$. final concentration) was added to a culture filtrate of Pediococcus cerevisiae $808 \mathrm{I}$ CRD (which was able to decompose methicillin when incubated with it for several hours at $\left.37^{\circ}\right)$ and the mixture $(25,50,100 \mu \mathrm{l}$. samples) was at once plated. A solution of methicillin ( $100 \mu \mathrm{g} . / \mathrm{ml}$ ), in $0.1 \mathrm{M}$-phosphate buffer (pH 6.5), was similarly plated. After incubation of the plates for $18 \mathrm{hr}$, equal volumes of the two solutions (with all three volumes of sample) gave identical zones of inhibition. The useful range of the assay was $0.5-20 \mu \mathrm{g}$. methicillin per well, or $0.02-\mathrm{I} \cdot 0 \mu \mathrm{g}$. broxil per well. The precision of the estimation was low, but this was unimportant in the experiments for which the assay was used.

Chemicals. Methicillin (2,6-dimethoxyphenylpenicillin) used in the development of the methicillin-dependent substrain was kindly given by $\mathrm{Mr}$ J. W. Lightbown, before it was generally available. In most of the subsequent work described in this paper, commercial supplies of methicillin were used. Broxil (6-( $\alpha$-phenoxypropionamido)penicillanic acid); phenoxymethylpenicillin (penicillin V) and $\alpha$-aminobenzylpenicillin (ampicillin) were gifts from Beecham Research Laboratories. Quinacillin (3-carboxy- 
2-quinoxalinylpenicillin) was given by Dr D. F. Spooner, and 6-aminopenicillanic acid was given by Dr D. L. Swallow. Stock (sterile filtered) solutions of penicillins were kept at $-15^{\circ}$.

Cephalosporin $\mathrm{C}$, cephalosporin $\mathrm{N}$ and bacitracin were provided by Professor E. P. Abraham. Dr D. L. Swallow gave 7-(phenylacetamido)-cephalosporanic acid. Vancomycin (from Eli Lilley and Co.) was given by Dr P. E. Reynolds.

Mevalonic acid (potassium salt) was provided by Dr G. Popják. Leucovorin (calcium salt of 5 -formyl-tetrahydropteroylglumatic acid) was given by the late Professor D. D. Woods. Pencillinase (a sterile filtrate of a broth culture of Bacillus licheniformis) was bought from Burroughs Wellcome.

\section{Table I. Development of the methicillin-requiring substrain of Pediococcus cerevisiae 8081}

Organisms were grown in partly defined medium $(5 \mathrm{ml}$.) containing increasing concentrations of methicillin. At intervals organisms were transferred from the highest concentration of methicillin in which growth had occurred into a fresh series of tubes. The inoculum for subculture I was $P$. cerevisiae 808I grown in medium without methicillin. After subculture 27 organisms were transferred to stab cultures in partly defined medium containing methicillin (100 $\mu \mathrm{g} . / \mathrm{ml}$.). This culture was called 808I CRD.

\begin{tabular}{|c|c|c|c|}
\hline Subculture & $\begin{array}{l}\text { Highest concn. } \\
\text { of methicillin } \\
\text { permitting growth } \\
(\mu \mathrm{g} . / \mathrm{ml} .)\end{array}$ & $\begin{array}{l}\text { Time of } \\
\text { incubation before } \\
\text { transfer } \\
\text { (hr) }\end{array}$ & $\begin{array}{l}\text { Lag period in } \\
\text { methicillin-free } \\
\text { medium } \\
\text { (hr) }\end{array}$ \\
\hline I & 10 & 28 & $<20$ \\
\hline 2 & 40 & 70 & $<20$ \\
\hline 3 & 20 & 48 & $<17$ \\
\hline 4 & 40 & 48 & $<17$ \\
\hline 5 & 40 & 70 & $<17$ \\
\hline 6 & 40 & 72 & $<$ I7 \\
\hline $7^{*}$ & 40 & 48 & $<18$ \\
\hline 8 & 50 & 72 & $<25$ \\
\hline 9 & 50 & 47 & $<23$ \\
\hline IO & 60 & 43 & $<22$ \\
\hline I I & 80 & 123 & • \\
\hline 12 & 100 & 120 & . \\
\hline 13 & IIO & 73 & $<24$ \\
\hline 14 & 140 & 108 & 24 \\
\hline 15 & 100 & I44 & 45 \\
\hline 16 & 150 & 95 & 40 \\
\hline I7 & 200 & 92 & $<24$ \\
\hline 18 & 300 & 147 & 45 \\
\hline 19 & 400 & 96 & 50 \\
\hline 20 & 400 & 96 & 60 \\
\hline $2 \mathrm{I}$ & 800 & I45 & 66 \\
\hline 22 & 600 & 95 & 65 \\
\hline 23 & 600 & 120 & 100 \\
\hline 24 & 400 & I 44 & $>144$ \\
\hline 25 & 600 & 145 & $>145$ \\
\hline 26 & 600 & 97 & $>97$ \\
\hline 27 & 600 & II 2 & $>112$ \\
\hline
\end{tabular}

* At subculture 7 (and in subsequent subcultures) the inoculum was increased from about $5 \times 10^{4}$ organisms to about $5 \times 10^{5}$ organisms. 


\section{RESULTS}

\section{Development of the methicillin-dependent substrain}

The course of development of this substrain is shown in Table I. Pediococcus cerevisiae 808 $\mathrm{I}$ was grown in a series of pairs of test tubes containing the partly defined medium, with methicillin at increasing concentrations. Usually the concentration of methicillin was doubled between each pair of tubes in a series (though sometimes the concentrations were closer than this), and one pair of tubes contained no drug. Organisms from the highest concentration of methicillin at which growth occurred in

\section{Table 2. Attempt to develop a benzylpenicillin-resistant substrain of Pediococcus cerevisiae 8081}

Organisms were grown in partly defined medium $(5 \mathrm{ml}$.) containing increasing concentrations of benzylpenicillin. At intervals organisms were transferred from the highest concentration of benzylpenicillin in which growth had occurred into a fresh series of tubes. The inoculum for subculture I was $P$. cerevisiae $808 \mathrm{I}$ grown in medium without methicillin. For brevity, steps where no resistance was gained have been omitted. After subculture 27 organisms were transferred to stab cultures in partly defined medium. This culture was called 808I PR (penicillin-resistant).

\begin{tabular}{|c|c|c|}
\hline Subculture & $\begin{array}{l}\text { Highest concn. of } \\
\text { benzylpenicillin } \\
\text { permitting growth } \\
(\mu \mathrm{g} . / \mathrm{ml} .)\end{array}$ & $\begin{array}{c}\text { Time of } \\
\text { incubation before } \\
\text { transfer } \\
\text { (hr) }\end{array}$ \\
\hline I & 0.8 & 29 \\
\hline 2 & $I \cdot O$ & 70 \\
\hline 3 & $I \cdot O$ & 48 \\
\hline 6 & 0.5 & 72 \\
\hline $7^{*}$ & $I \cdot O$ & 49 \\
\hline IO & 1.0 & 42 \\
\hline I I & I. 5 & 123 \\
\hline I 2 & $2 \cdot 5$ & I 20 \\
\hline 16 & 3.0 & 95 \\
\hline 20 & $3 \cdot 0$ & 96 \\
\hline $2 \mathrm{I}$ & $4 \cdot 0$ & 145 \\
\hline 24 & $5^{\circ} 0$ & 145 \\
\hline 26 & 4.0 & 97 \\
\hline 27 & 3.0 & 112 \\
\hline
\end{tabular}

* At subculture 7 (and subsequently) the inoculum was increased from about $5 \times 10^{4}$ organisms to about $5 \times 10^{5}$ organisms.

one series of tubes were used to inoculate a fresh series of tubes. In the earlier subcultures (I-IO) transfers were made at intervals of 2-3 days, and only a low degree of resistance developed. The size of the inoculum was increased after subculture 6 and longer periods were allowed between transfers (after subculture 10). During subcultures $\mathrm{I} I-20$ the degree of resistance gradually increased; no large increase in resistance occurred at any one step. There was a gradual increase in the lag period before growth became visible in methicillin-free medium. By passage 20, growth appeared only after a lag of about $72 \mathrm{hr}$ in methicillin-free medium. The lag was shorter in medium containing methicillin, although the difference of the lag in this medium and in methicillin-free medium was not striking at this stage, probably because the lowest concentration of methicillin that was being used in subculture 20 was $200 \mu \mathrm{g}$. $/ \mathrm{ml}$., which was a higher concentration than subsequently proved to optimal for rapid 
growth of the dependent organisms. Resistance did not increase further between subcultures 2I and 27, but the failure of the organisms to grow in the absence of methicillin became more and more obvious. By subculture 27 organisms grew rapidly and heavily in the presence of methicillin (I00 $\mu \mathrm{g} . / \mathrm{ml}$.), but did not show any growth within 5 days in its absence.

Attempt to develop a substrain resistant to benzylpenicillin. Serial transfers of Pediococcus cerevisiae $808 \mathrm{I}$ were similarly made in medium containing increasing concentrations of benzylpenicillin (Table 2). As in the development of resistance to methicillin, it was necessary to increase the size of the inoculum and to lengthen the time between subcultures in order to obtain resistant organisms. Even so, the degree of resistance to benzylpenicillin that was achieved after 27 subcultures was only about fourfold. The resistant organisms grew in the absence of benzylpenicillin with a lag period little longer than that of the parent strain; benzylpenicillin did not stimulate growth.

\section{Properties of the methicillin-requiring organisms}

Response to methicillin. The methicillin-requiring organisms were not highly resistant to methicillin; growth was inhibited by a concentration of methicillin about 40 times higher than was inhibitory for the parent strain. There was therefore only a limited range of concentration of methicillin within which growth occurred (Fig.I). About $40-100 \mu \mathrm{g}$. methicillin/ml. was optimal for growth of the organisms within $50 \mathrm{hr}$ in the partly defined medium. On longer incubation, organisms were able to grow over a wider range of methicillin concentration and the highest turbidity was eventually reached in relatively low concentrations of it. When an inoculum of less than about $10^{4}$ organisms was used, no growth occurred in methicillin-free medium, but when about $10^{5}$ (or more) organisms were used, then limited growth (about 0.2 on the colorimeter scale) occurred in methicillin-free medium after 2-4 days, depending on the volume of the medium inoculated. This growth never approached the turbidity given by the parent strain in methicillin-free medium.

The response of Pediococcus cerevisiae 808 I CRD to methicillin on solid medium is illustrated in Pl. I, fig. I. Immediately adjacent to the hole in the medium where methicillin was placed, there was a zone showing no growth, presumably because the methicillin was at an inhibitory concentration. Farther from the hole there was a zone of confluent growth, beyond which there was again no growth, presumably because there the concentration of methicillin had become too low. In this outer region a few single colonies appeared, probably from organisms which had reverted to ability to grow in absence of methicillin.

When incubated in partly defined medium containing methicillin ( $100 \mu \mathrm{g} . / \mathrm{ml}$.), Pediococcus cerevisiae 808 r CRD showed a longer lag phase before turbidity appeared than did the parent strain (growing without methicillin), although the rate of logarithmic growth of the methicillin dependent strain was only slightly lower (Fig. 2). The final turbidity of cultures of $P$. cerevisiae $808 \mathrm{I}$ CRD (with any concentration of methicillin) was lower (at best about $I^{\cdot} 5^{-2 \cdot 0}$ on the colorimeter scale) than that of cultures of the parent strain grown without methicillin (about $2 \cdot 0-2 \cdot 5$ ). The turbidity of cultures of both strains did not decrease (within 7 days at $37^{\circ}$ ) after maximum turbidity had been reached.

Colony counts were made during growth of Pediococcus cerevisiae $808 \mathrm{I}$ CRD from a small inoculum (Fig. 3). The number of organisms able to form colonies in medium 
containing methicillin increased, and eventually reached about $4 \times 10^{8} / \mathrm{ml}$, after which there was a decrease in the number that were viable. Initially, no organisms could be detected that were able to form colonies in methicillin-free medium, but such organisms subsequently appeared in the proportion of about I among $10^{5}$ methicillinrequiring organisms.

Other properties. A characteristic feature of Pediococcus cerevisiae is that 5-formyltetrahydropteroylglutamic acid (leucovorin) is the only form of folic acid that supports growth in a medium which otherwise lacks the vitamin. The parent strain and the methicillin-requiring strain did not grow when leucovorin was omitted from the medium, even when it was supplemented with pteroylglutamic acid $(2 \mathrm{~m} \mu \mathrm{g} . / \mathrm{ml}$.). Both strains grew when leucovorin was added, and the amount of growth (turbidity) was graded over the range of $0-0.1 \mathrm{~m} \mu \mathrm{g}$. leucovorin $/ \mathrm{ml}$. The parent strain grew in partly defined medium (after a lag of about $40 \mathrm{hr}$ ) when leucovorin was replaced by thymidine ( $0 . \mathrm{I} \mu \mathrm{g} . / \mathrm{ml}$.), although the final turbidity was only about one third of that obtained with leucovorin. The methicillin-requiring strain did not grow (within $120 \mathrm{hr}$ ) when leucovorin was replaced by thymidine.

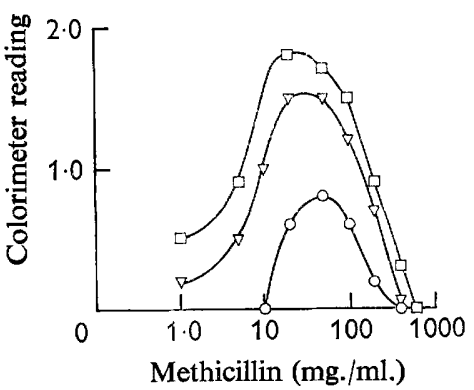

Fig. 1

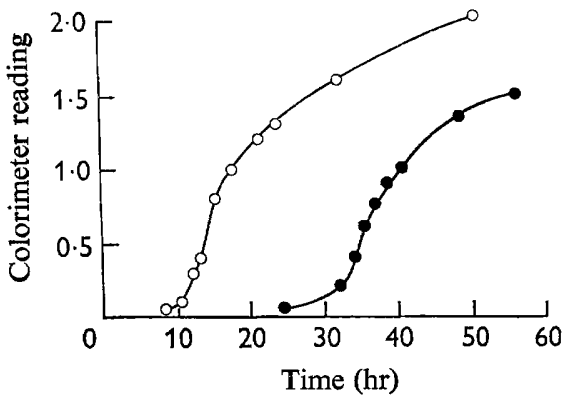

Fig. 2

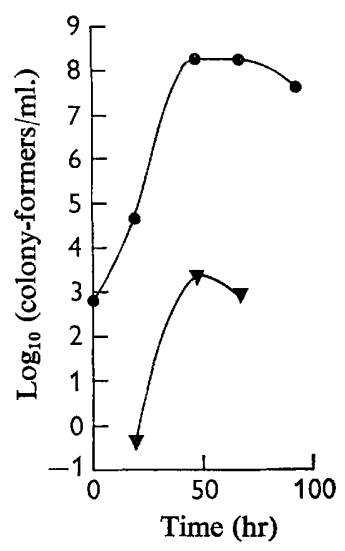

Fig. 3

Fig. I. Response of Pediococcus cerevisiae 808 I CRD to methicillin. A series of $100 \mathrm{ml}$. conical flasks was prepared, containing partly defined medium $(50 \mathrm{ml}$.) with various concentrations of methicillin. Each flask was inoculated with $0.1 \mathrm{ml}$. of an overnight culture of $P$. cerevisiae $8081 \mathrm{CRD}$, and incubated at $37^{\circ}$. At intervals samples were removed and their turbidities were read in the EEL colorimeter as described in the Methods section: $O$, after $21 \mathrm{hr} ; \nabla$, after $47 \mathrm{hr}, \square$, after $63 \mathrm{hr}$.

Fig. 2. Growth of Pediococcus cerevisiae 808I and 808I CRD in partly defined medium. Two $150 \mathrm{ml}$. flasks were prepared, each containing $100 \mathrm{ml}$. medium, and to one of which methicillin $(100 \mu \mathrm{g} . / \mathrm{ml}$.) was added. Overnight liquid-cultures of $P$. cerevisiae $808 \mathrm{I}$ and $808 \mathrm{I}$ CRD were diluted (sterile water) to give colorimeter readings of 0.02 , and $\mathrm{I} \cdot 0 \mathrm{ml}$. of each suspension. was used as an inoculum: the flask without methicillin was inoculated with $P$. cerevisiae $808 \mathrm{I}$, and that containing methicillin with $P$. cerevisiae $808 \mathrm{I}$ CRD. The flasks were incubated at $37^{\circ}$ and samples were removed at intervals, and their turbidities were read in the EEL colorimeter as described in the Methods section. $O, P$. cerevisiae $8081 ; O, P$. cerevisiae 808 I CRD.

Fig. 3. Colony counts during growth of Pediococcus cerevisiae 808I CRD from a small inoculum. A $100 \mathrm{ml}$. conical flask containing $50 \mathrm{ml}$. of partly defined medium plus methicillin ( $100 \mu \mathrm{g} . / \mathrm{ml}$.) was inoculated with $0.1 \mathrm{ml}$. of a I $/ 1000$ dilution of a $48 \mathrm{hr}$ culture of $P$. cerevisiae $808 \mathrm{I}$ CRD. The flask was incubated at $37^{\circ}$ and samples were removed at intervals for plating in Difco CF assay medium (+ leucovorin). Count in agar containing methicillin $(100 \mu \mathrm{g} . / \mathrm{ml}$ ) ; $\nabla$, count in agar without methicillin. 
Neither Pediococcus cerevisiae 808I nor 808I CRD grew as rapidly or as heavily at $30^{\circ}$ as at $37^{\circ}$, either in defined or in partly defined media. At $30^{\circ}$, methicillin was still required for growth of $P$. cerevisiae $808 \mathrm{I}$ CRD in both media.

Under anaerobic conditions, Pediococcus cerevisiae 808I CRD did not grow in defined medium, with or without methicillin. The parent strain grew to a limited extent under anaerobic conditions in defined medium without methicillin. Addition of yeast extract to defined medium enabled $P$. cerevisiae 808 I CRD to grow anaerobically within $60 \mathrm{hr}$ in the presence and in the absence of methicillin. Anaerobic growth with yeast extract after shorter periods of incubation was not examined.

Some effects of oleic acid on growth of Pediococcus cerevisiae 808I CRD were investigated. In defined medium, oleic acid (adjusted to $\mathrm{pH} 6.5$ before addition prior to autoclaving of the medium) at $0.1 \mathrm{mg}$. $/ \mathrm{ml}$. inhibited growth in the presence of methicillin, but did not inhibit at $0.0 \mathrm{I} \mathrm{mg} . / \mathrm{ml}$. Oleic acid (0.0I-0.1 mg./ml.) did not replace acetate for growth, with or without methicillin.

When partly defined medium had been extracted three times with ether or chloroform at $\mathrm{pH} 4.0$, or $6.5(0.5 \mathrm{ml}$. solvent $/ \mathrm{ml}$. medium at each extraction), methicillin was still required for growth of Pediococcus cerevisiae 808I CRD: medium extracted with chloroform at $\mathrm{pH} 4.0$ gave slightly poorer growth than did the unextracted or ether-extracted medium. When testing these extracted media, one from each pair of duplicate tubes was closed with a metal cap instead of a cotton-wool plug. It was thought possible that materials which caused the requirements for methicillin (by $P$. cerevisiae $808 \mathrm{I}$ CRD) might have come from cotton-wool plugs. However, this was not the case, because the growth responses in duplicate tubes, with caps or plugs, were the same.

Growth responses to other derivatives of 6-aminopenicillanic acid, and to other compounds. Several compounds were tested for ability to support growth of Pediococcus cerevisiae 808I CRD in the partly defined medium (Table 3), and determinations were made of their growth-inhibitory concentrations for the parent strain. All the derivatives of 6-aminopenicillanic acid tested had activity as growth factors for $P$. cerevisiae 808I CRD over limited ranges of concentration. Those which inhibited growth of the parent strain at the lowest concentrations were also effective at the lowest concentrations as growth factors for the substrain. However, none of these compounds gave growth that was as rapid or as heavy as that obtained with optimal concentrations of methicillin. Generally the methicillin-requiring strain was unable to grow in concentrations of penicillins much higher than those which caused inhibition of growth of the parent strain, i.e. $P$. cerevisiae $808 \mathrm{I}$ CRD had appreciable resistance only to methicillin and was not cross-resistant to other penicillins to any marked extent.

The response of Pediococcus cerevisiae 808I CRD to two different amounts of benzylpenicillin in solid medium is illustrated in P1.r, figs. 2, 3. The zone of confluent growth was farther from the centre well (containing penicillin) when the larger amount of penicillin was used.

Loss of activity (as a growth factor) on hydrolysis of methicillin. Although methicillin is considerably less sensitive to penicillinase than is benzylpenicillin, it is slowly hydrolysed by the enzyme to a derivative of penicilloic acid. Hydrolysis with alkali gives the same product quite rapidly, while acid-hydrolysis rapidly leads to the formation of a penillic acid derivative. Methicillin (4 mg.) in bicarbonate buffer was incubated with penicillinase (Bacillus licheniformis culture filtrate, $0.2 \mathrm{ml}$.) in Warburg 
flasks, as described by Abraham (1955), and a control (methicillin without penicillinase) was also included. After evolution of carbon dioxide had ceased ( $18 \mathrm{hr}$ ) the contents of the flasks were washed out quantitatively and made up to $10 \mathrm{ml}$.

Methicillin (2I mg.) was also dissolved in $0.1 \mathrm{~N}-\mathrm{HCI}\left(4.2 \mathrm{ml}\right.$.), incubated at $37^{\circ}$ for $2 \mathrm{hr}$ and then neutralized with $0 . \mathrm{I} \mathrm{N}-\mathrm{NaOH}$. Another sample of methicillin ( $53 \mathrm{mg}$.) was dissolved in $\mathrm{I} \cdot 0 \mathrm{~N}-\mathrm{NaOH}(8 \mathrm{ml}$.), kept at room temperature for $\mathrm{I} \mathrm{hr}$ and then neutralized with $4 \mathrm{~N}-\mathrm{HCl}$. These two solutions were diluted to the equivalent of $\mathrm{I} \mathrm{mg.} \mathrm{(acid-}$ hydrolysate) or $0.5 \mathrm{mg}$. (alkali-hydrolysate) of original methicillin $/ \mathrm{ml}$. Assays with Staphylococcus aureus showed that at least $95 \%$ of the methicillin in these two

Table 3. Activities of various compounds as growth factors for Pediococcus cerevisiae $8081 C R D$ and as inhibitors of growth of $P$. cerevisiae 8081

Organisms were grown in partly defined medium (for about 4-5 days) in a series of tubes containing the compound under test; generally the concentration of the compound was trebled between each pair of tubes in a series.

\section{Compound}

Phenoxymethylpenicillin Benzylpenicillin

$\alpha$-Phenoxyethylpenicillin

(Broxil)

$\alpha$-Aminobenzylpenicillin

Quinacillin (3-carboxy-2-

quinoxalinylpenicillin)

Methicillin

6-Aminopenicillanic acid

Cephalosporin $\mathrm{N}$

Cephalosporin $\mathrm{C}$

7-(Phenylacetamido)-

cephalosporanic acid

Bacitracin

Vancomycin

Cycloserine

2,6-Dimethoxybenzoic acid

Concn. ( $\mu \mathrm{g} . / \mathrm{ml}$.$) causing:$

$\begin{array}{cc}\begin{array}{c}\text { Growth of methicillin- } \\ \text { dependent strain } \\ 808 \mathrm{I} \text { CRD }\end{array} & \begin{array}{c}\text { Inhibition of } \\ \text { parent strain } 808 \mathrm{I}\end{array} \\ 0.1-0.3 & 0.1 \\ 0.1-0.5 & 0 \cdot \mathrm{I}-0.5 \\ 0.5 & 0 \cdot 3-1 \cdot 0 \\ \mathrm{I} \cdot 0 & \mathrm{I} \cdot 0 \\ 30 & 100 \\ 30-300 & 10-20 \\ 50-100 & >100 \\ \text { I00 } & >100 \\ \text { I00* } & >100 \\ \text { I0* } & . \\ \text { Inactive } & 30-100 \\ \text { Inactive } & . \\ \text { Inactive } & . \\ \text { Inactive } & .\end{array}$

* Very slight growth after $100 \mathrm{hr}$.

solutions had been hydrolysed to non-inhibitory products. Control solutions of methicillin (without acid or alkali) were similarly incubated and diluted. When filtered to sterilize and added to partly defined medium ( $5 \mathrm{ml}$. final volume) the solutions of penicillinase, acid-or alkali-hydrolysed methicillin $(0.25-2 \cdot 0 \mathrm{ml}$.) were unable to support growth of Pediococcus cerevisiae 808I CRD, whereas all the controls gave good growth.

\section{Disappearance of methicillin during growth of cultures of Pediococcus cerevesiae 8081CRD}

A culture of Pediococcus cerevisiae 808I CRD was grown in partly defined medium (200 ml.) containing methicillin (100 $\mu \mathrm{g} . / \mathrm{ml}$.). At intervals during incubation, samples (Io $\mathrm{ml}$.) were removed and their turbidities and $\mathrm{pH}$ values measured. Each sample was then adjusted to $\mathrm{pH} 6.5$, organisms removed by centrifugation and the supernatant 
fluid Seitz-filtered. The concentration of methicillin in each sample was then found by plate assay; the results are shown in Fig. 4. The initial $\mathrm{pH}$ value of the medium (after autoclaving) was $6 \cdot 2$, but as growth increased the $\mathrm{pH}$ value decreased to a final value of about 4.5 . The concentration of methicillin began to decrease at about the middle of the logarithmic phase of growth, when the medium was about $\mathrm{pH} 5$. The rate at which methicillin subsequently disappeared from the medium was about the same as the rate of disappearance when methicillin ( $100 \mu \mathrm{g} . / \mathrm{ml}$.) was incubated in 0.1 M-acetate buffer ( $\mathrm{pH} 4.5$ ), at $37^{\circ}$. There was no appreciable disappearance of methicillin or change of $\mathrm{pH}$ value when autoclaved uninoculated medium was incubated at $37^{\circ}$ for $60 \mathrm{hr}$.

To establish whether or not the disappearance of methicillin had been due only to the acidity of the medium, a culture of Pediococcus cerevisiae 808 I CRD was grown in partly defined medium containing an optimal concentration of broxil ( $\mu \mathrm{g} . / \mathrm{ml}$.), which is a penicillin that is relatively stable to acid. Throughout the growth of this culture the medium was maintained at $\mathrm{pH} 6.5$ by regulated addition of $2 \mathrm{~N}-\mathrm{NaOH}$. Because of the shape of the culture vessel it was not possible to suspend organisms evenly (for measurement of turbidity) without very considerable agitation of the medium, which tended to delay or even prevent further growth. Consequently the volume of alkali consumed was taken as a measure of growth. The turbidity of the medium and the amount of bacterial growth clinging to the vessel were very roughly estimated by eye. Growth so assessed corresponded in its time of first appearance, and in its increase, with the consumption of alkali, although in the later stages of the experiment the organisms might have been producing acid without further increase in their mass. At intervals samples were withdrawn from the apparatus, organisms removed by centrifugation and the sample assayed for broxil; results are shown in Fig. 5. The concentration of broxil remained unchanged until moderate growth had occurred. As before, the broxil disappeared from the medium during the phase of most rapid growth, and even when all the broxil had disappeared, alkali continued to be consumed, at a slightly slower rate. This rate was not accelerated when more broxil was added (to give $\mathrm{I} \cdot 0 \mu \mathrm{g} . / \mathrm{ml}$.) and the drug again disappeared from the medium. When the experiment was stopped, $30 \mathrm{ml}$. of $2 \mathrm{~N}-\mathrm{NaOH}$ had been used. If each molecule of glucose in the medium ( $350 \mathrm{ml}$., containing $8.75 \mathrm{~g}$. glucose) had been broken down to two molecules of lactic acid, then $48.6 \mathrm{ml}$. of $2 \mathrm{~N}-\mathrm{NaOH}$ would have been required to maintain the $\mathrm{pH}$ value at 6.5 .

A similar experiment was done in which organisms were grown at constant $\mathrm{pH}$ value in the presence of methicillin (100 $\mu \mathrm{g} . / \mathrm{ml}$.). As before, the methicillin began to disappear from the medium when moderate growth had occurred and consumption of alkali continued after all the methicillin had been destroyed. The organisms grew rather more heavily and quickly with methicillin than they did with broxil, and more alkali ( $42 \mathrm{ml}$.) was needed to maintain the $\mathrm{pH}$ at 6.5 .

In other experiments, organisms were harvested after growing in the ordinary way in partly defined medium containing methicillin ( $100 \mu \mathrm{g} . / \mathrm{ml}$.) or broxil (I $\mu \mathrm{g} . / \mathrm{ml}$.). The organisms were washed and resuspended in $0.1 \mathrm{M}$-phosphate buffer ( $\mathrm{pH} \mathrm{6.5)}$ to about equiv. I mg. dry wt $/ \mathrm{ml}$. The culture filtrates were Seitz-filtered and adjusted to $\mathrm{pH}$ 6.5. Organisms and culture filtrates were seperately incubated overnight at $37^{\circ}$ with methicillin (100 $\mu \mathrm{g} . / \mathrm{ml}$.), which was assayed at the beginning and end of the incubation. The washed organisms did not destroy the drug. However, the filtrate from broxil- 
grown organisms completely destroyed the methicillin, and only about $20 \%$ of the drug remained after incubation with the filtrate from methicillin-grown organisms. In another experiment, organisms grown with methicillin were tested manometrically for penicillinase activity, but none was found. Culture filtrates could not be assayed for penicillinase in this way because of the relatively high buffer capacity of the medium.

Three cultures of Pediococcus cerevisiae 808 I CRD were grown in partly defined medium ( $350 \mathrm{ml} . / 500 \mathrm{ml}$.flask) containing methicillin (I00 $\mu \mathrm{g}$. $/ \mathrm{ml}$.). The cultures were removed from each flask at a different stage of growth, centrifuged, and the supernatant fluids were adjusted to $\mathrm{pH} 6 \cdot 5$ and then Seitz-filtered. The three filtrates were incubated overnight with methicillin (100 $\mu \mathrm{g} . / \mathrm{ml}$.) which was assayed at the beginning and

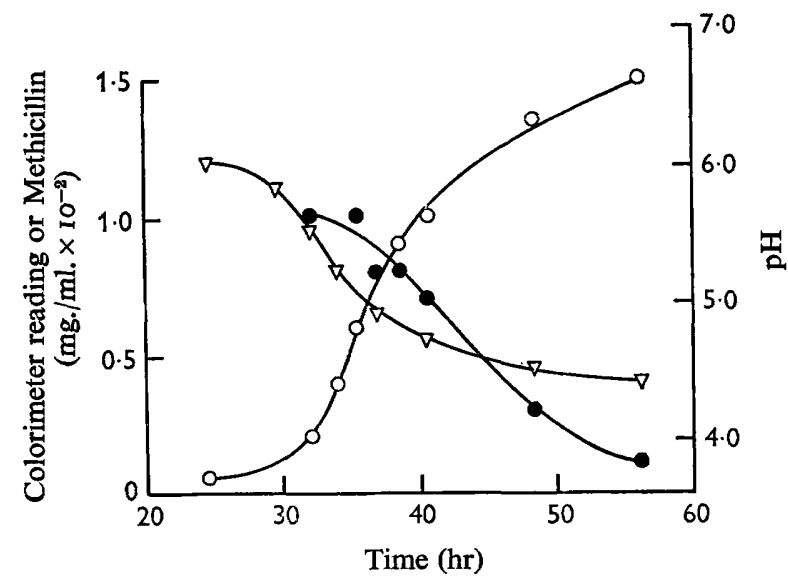

Fig. 4

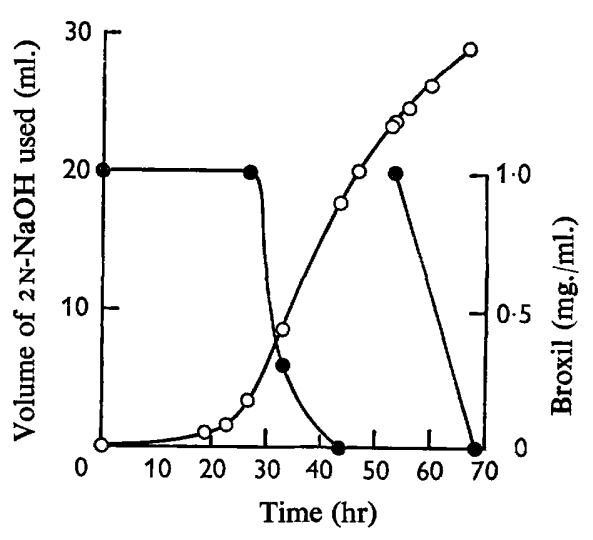

Fig. 5

Fig. 4. Changes in the $\mathrm{pH}$ value and the concentration of methicillin in the medium during growth of Pediococcus cerevisiae 808I CRD. Organisms were grown in partly defined medium containing methicillin $(100 \mu \mathrm{g} . / \mathrm{ml}$.) and samples were removed at intervals. $O$, Colorimeter readings; 0 , methicillin concentration; $\nabla, \mathrm{pH}$ value.

Fig. 5. Changes in the concentration of broxil in the medium during growth of Pediococcus cerevisiae $808 \mathrm{I} \mathrm{CRD}$ at a constant $\mathrm{pH}$ value. Organisms were grown in partly defined medium containing broxil ( $1 \mu \mathrm{g} . / \mathrm{ml}$.) and samples were removed at intervals and assayed for broxil. The medium was maintained at $\mathrm{pH} 6.5$ by the regulated addition of alkali (see Methods section). After all the broxil had disappeared $(52 \mathrm{hr})$ more broxil was added to give again I $\mu \mathrm{g} . / \mathrm{ml}$. $\bigcirc$, Volume of $2 \mathrm{~N}$-sodium hydroxide used; $O$, concentration of broxil.

end of this period, with the following results. The $22 \mathrm{hr}$ filtrate (initially $\mathrm{pH} 5.4$ ) did not inactivate methicillin; the $47 \mathrm{hr}$ and $67 \mathrm{hr}$ filtrates (initially $\mathrm{pH} 4.3$ and $4^{\circ} \mathrm{O}$, respectively) both destroyed about $75 \%$ of the methicillin. The $22 \mathrm{hr}$ filtrate itself contained methicillin (about $25 \mu \mathrm{g} . / \mathrm{ml}$.); the other two filtrates did not.

Some properties of the methicillin-destroying factor from Pediococcus cerevisiae 8081 and $8081 C R D$. At first, production in the culture of material which destroyed the antibiotic potency of methicillin was assumed to be a special property of the methicillindependent strain. However, culture filtrates of the parent strain, grown in partly defined medium without methicillin, also inactivated methicillin at a similar rate. Some properties of the methicillin-destroying factor (or factors) were examined, and 
no differences were found between the factor from filtrates of the parent or dependent strain.

The factor does not seem to be an enzyme. Its ability to destroy methicillin was not diminished by boiling culture filtrates for 15 min. at $\mathrm{pH} 3.5$ or 6.5 , but was considerably decreased by boiling at $\mathrm{pH} 10 \cdot 2$ for $\mathrm{I} 5 \mathrm{~min}$. On overnight dialysis against water, most of the methicillin-destroying material was diffusible. The factor was stable for at least several months in culture filtrates kept at $2^{\circ}$. Filtrates could be evaporated (under reduced pressure) to one tenth of their original volume, or freezedried, without loss of the methicillin-destroying factor.

The inactivation of methicillin became progressively less rapid between $\mathrm{pH} 6.0$ and $\mathrm{pH} 7.5$ (about $50 \%$ diminution of the rate of disappearance). At $\mathrm{pH} 6.5$, benzylpenicillin was inactivated at about the same rate as methicillin, i.e. the half life of the compound (initially $100 \mu \mathrm{g} . / \mathrm{ml}$.) in the culture filtrate was about $5 \mathrm{hr}$. Culture filtrates were also able to inactivate 6-aminopenicillanic acid at a similar rate.

\section{Growth of Pediococcus cerevisiae 8081 CRD in the absence of penicillin derivatives}

Addition of Difco yeast extract ( $1 \%, w / v)$, Oxoid tomato juice ( $10 \%, v / v)$ or Oxoid liver infusion (0.16\%) to partly defined medium did not enable Pediococcus cerevisiae $808 \mathrm{r}$ CRD to grow (within $50 \mathrm{hr}$ ) in the absence of methicillin. In tryptose glucose broth, growth occurred only when the medium was supplemented with methicillin (I00 $\mu \mathrm{g} . / \mathrm{ml}$. was optimal). In the absence of methicillin, addition of Oxoid peptone $(\mathrm{I} \cdot 5 \%, \mathrm{w} / \mathrm{v})$ to partly defined medium gave light growth of $P$. cerevisiae 808I CRD (within $50 \mathrm{hr}$ ). Better growth was obtained in peptone water + glucose, and addition of Difco yeast extract ( $\mathrm{I} \%, \mathrm{w} / \mathrm{v})$ gave a further improvement. The organisms which grew in peptone yeast-extract glucose (PYG) medium did not grow when transferred to the partly defined medium, unless this was supplemented with methicillin.

When added together to partly defined medium (without methicillin) peptone and yeast extract were much less effective in promoting growth: it seemed therefore that partly defined medium contained material which inhibited the growth that could occur in PYG medium. The various components of the partly defined medium (at the concentrations used in that medium) were therefore seperately added to PYG medium which was then tested for ability to support growth of Pediococcus cerevisiae 808I CRD in the absence of methicillin. In this way it was found that sodium acetate $(2 \%, w / v)$ was the material from the partly defined medium which inhibited growth in PYG medium. The inhibition by sodium acetate was overcome by the addition of methicillin (100 $\mu \mathrm{g} . / \mathrm{ml}$.) to PYG medium.

\section{Effects of sodium acetate on growth of Pediococcus cerevisiae 8081 CRD}

The growth of liquid cultures of Pediococcus cerevisiae 808I CRD in fully defined medium, with and without sodium acetate, was investigated (Table 4). Medium containing acetate did not support growth unless methicillin was added (about $20 \mu \mathrm{g}$. $/ \mathrm{ml}$. was optimal), but when acetate was omitted there was no growth even when methicillin was present. However, when yeast extract was added to medium without acetate, rapid growth occurred in the absence of methicillin. When acetate was present as well as yeast extract, growth in the absence of methicillin occurred only after a relatively long lag, but this inhibition by acetate could be overcome by adding methicillin. 
Several compounds were tested for ability to replace acetate as a growth factor in the defined medium, with and without methicillin (Table 5). Of these compounds, only propionic, butyric and lipoic acids were effective; none gave such rapid or heavy growth as did acetate. Lipoic acid is known to be an 'acetate replacing factor' in lactic acid bacteria (Reed, De Busk, Gunsalus \& Hornberger, 195I). However, lipoic acid had only a limited ability to replace acetate for growth of Pediococcus cerevisiae $808 \mathrm{I}$ or $808 \mathrm{I}$ CRD. With the parent strain, which also required acetate, lipoic acid (10 $\mu \mathrm{g} . / \mathrm{ml}$.) supported moderate growth in absence of acetate, but higher (100 $\mu \mathrm{g} . / \mathrm{ml}$.) or lower (I $\mu \mathrm{g} . / \mathrm{ml}$.) concentrations gave very slight growth; lipoic acid at $100 \mu \mathrm{g} . / \mathrm{ml}$. inhibited growth in the presence of acetate $(20 \mathrm{mg} . / \mathrm{ml}$.). With the methicillin-dependent strain, lipoic acid $(5 \mu \mathrm{g} . / \mathrm{ml}$.) gave moderate growth in defined medium without acetate, with or without methicillin, but higher or lower

\section{Table 4. Growth of Pediococcus cerevisiae 8081 CRD in defined medium with various additions}

Defined medium ( $5 \mathrm{ml}$.) in test-tubes was inoculated with $P$. cerevisiae $808 \mathrm{I}$ CRD and incubated at $37^{\circ}$.

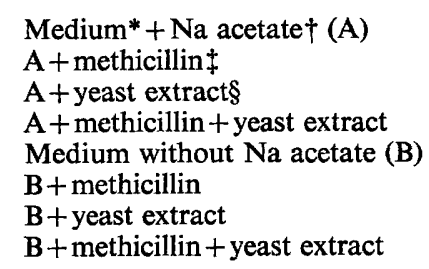

\begin{tabular}{|c|c|c|}
\hline \multicolumn{3}{|c|}{ Time of incubation (hr) } \\
\hline 20 & 40 & 60 \\
\hline \multicolumn{3}{|c|}{ Relative growth (turbidity) } \\
\hline - & - & - \\
\hline \pm & + & + \\
\hline 二 & - & $++t$ \\
\hline+ & +++ & +++ \\
\hline- & - & - \\
\hline - & - & - \\
\hline+ & ++ & ++ \\
\hline- & + & + \\
\hline
\end{tabular}

* Medium: defined, without $\mathrm{Na}$ acetate.

$\dagger \mathrm{Na}$ acetate ${ }_{3} \mathrm{H}_{2} \mathrm{O}: 20 \mathrm{~g}$. $/ \mathrm{l}$; ; added (before autoclaving) as a solution $(20 \%, \mathrm{w} / \mathrm{v}$ ) adjusted to pH 6.5.

¥ Methicillin: $100 \mu \mathrm{g} . / \mathrm{ml}$; added as a sterile (filtered) solution after autoclaving.

$\S$ Yeast extract (Difco): $2 \%(\mathrm{w} / \mathrm{v})$; added before autoclaving.

concentrations of lipoic acid did not support growth. No improvement in growth of the methicillin dependent strain without acetate resulted when sodium pyruvate ( $3 \mathrm{mg} . / \mathrm{ml}$.) was added with lipoic acid. Mevalonic acid did not replace acetate, at the concentration tested, nor did several 'two carbon' compounds and other substances.

The amounts of sodium acetate or of yeast extract needed to support growth of the methicillin-dependent strain were compared (Table 6). Concentrations of sodium acetate above $2 \%(\mathrm{w} / \mathrm{v})$ retarded growth even in the presence of methicillin, and concentrations lower than about $0.1 \%$ were insufficient to support growth. A concentration of about $0.5 \%$ was optimal, giving the most rapid and heavy growth in the presence of methicillin. With this concentration of sodium acetate, a limited amount of growth without methicillin occurred. At least $\mathrm{I}-2 \%(\mathrm{w} / \mathrm{v})$ sodium acetate was needed to cause a delay of growth in the presence of yeast extract (when methicillin was omitted). 
Although the organisms which grew in the presence of yeast extract when methicillin and acetate were omitted were not identical with the parent strain (because their growth was inhibited by acetate), it did seem possible that these organisms might be variants distinct from the organisms which required methicillin in medium containing acetate and no yeast extract. To examine this possibility, growth on solid media was investigated (Table 7). A culture of Pediococcus cerevisiae 808I CRD was diluted and

Table 5. Ability of various compounds to replace sodium acetate for the growth of Pediococcus cerevisiae 8081 CRD

The compound being tested (in solution adjusted to $\mathrm{pH} 6 \cdot 0-6 \cdot 5$ and filtered to sterilize) was added, after autoclaving, to a series of tubes of defined medium $(5 \mathrm{ml}$./tube) without sodium acetate with methicillin $30 \mu \mathrm{g} . / \mathrm{ml}$. Each compound was tested at two or more concentrations. Tubes were inoculated with $P$. cerevisiae $808 \mathrm{I}$ CRD and incubated at $37^{\circ}$.

\section{Compound}

Formic acid

Propionic acid

Butyric acid

Valeric acid

Oleic acid

Lipoic acid

Coenzyme A

Acetyl coenzyme A

Mevalonic acid ( $\mathbf{K}^{+}$salt)

Yeast extract (Difco)

Acetaldehyde

Ethanol

Glycollic acid

Glycolaldehyde

Ethyleneglycol

Glyoxylic acid

Glyoxal

Oxalic acid

Glycine

Ethanolamine

DL-serine

$\mathrm{Na}$ pyruvate

DL-lactic acid

Trisodium citrate. $2 \mathrm{H}_{2} \mathrm{O}$

Succinic acid

Potassium hydrogen phthalate

$\mathrm{N}$-acetylglucosamine

$\mathrm{Na}$ acetate. $3 \mathrm{H}_{2} \mathrm{O}$

$\mathrm{NaCl}$

\begin{tabular}{|c|c|}
\hline $\begin{array}{l}\text { Concentration } \\
(\mathrm{mg} . / \mathrm{ml} .)\end{array}$ & $\begin{array}{c}\text { Growth after } \\
40 \mathrm{hr}\end{array}$ \\
\hline$I-6$ & - \\
\hline $2-10$ & $+(\mathbf{M})$ \\
\hline $2 \cdot 5$ & $\pm(\mathrm{M})$ \\
\hline 3-I5 & - \\
\hline $0.0 \mathrm{I}-0 . \mathrm{I}$ & - \\
\hline 0.01 & + \\
\hline $0.000 I-0 . I$ & - \\
\hline $0.000 I-0 . I$ & \pm \\
\hline 0.7 & - \\
\hline $10-20$ & +++ \\
\hline I-6 & - \\
\hline I-6 & - \\
\hline $2-I I$ & - \\
\hline $0.5-3$ & - \\
\hline $2-9$ & - \\
\hline$I-3$ & - \\
\hline $2-9$ & - \\
\hline$I-4$ & - \\
\hline $2-I I$ & - \\
\hline $2-9$ & - \\
\hline$I-4$ & - \\
\hline $3-16$ & - \\
\hline $3-14$ & - \\
\hline 43 & - \\
\hline 17 & - \\
\hline 30 & - \\
\hline $0.5-2.5$ & - \\
\hline $10-20$ & $++(\mathbf{M})$ \\
\hline$I-20$ & - \\
\hline
\end{tabular}

$\mathrm{M}=$ Growth only in presence of methicillin ( $20 \mu \mathrm{g} . / \mathrm{ml}$. optimal).

plated in media of various compositions. For comparison, organisms of the parent strain were similarly plated. Because of the variability of the number of organisms occurring in one cluster in liquid cultures, differences in counts of less than tenfold in different media were not considered to be significant. Virtually all the clusters of organisms in the culture of $P$. cerevisiae 808 I CRD gave colonies on medium without acetate but supplemented with yeast extract, with or without methicillin. In medium containing acetate, most of the organisms grew only when methicillin was present, with or without yeast extract. 


\section{Table 6. Quantitative requirements for sodium acetate and yeast} extract for growth of Pediococcus cerevisiae 8081 CRD

Organisms were incubated in a series of tubes containing various concentrations of sodium acetate or yeast extract, with $(+M)$ and without $(-M)$ methicillin. Methicillin $30 \mu \mathrm{g} . / \mathrm{ml}$. in defined medium, $50 \mu \mathrm{g} . / \mathrm{ml}$. in partly defined medium. Sodium acetate $3 \mathrm{H}_{2} \mathrm{O}$ (adjusted to $\mathrm{pH} 6 \cdot 5$ ) Difco yeast extract, added before autoclaving.

\begin{tabular}{|c|c|c|c|c|}
\hline \multirow{2}{*}{$\begin{array}{c}\text { Medium } \\
\text { (without sodium } \\
\text { acetate) }\end{array}$} & \multicolumn{2}{|c|}{ Concn. $(\% w / v)$ of: } & \multicolumn{2}{|c|}{ Growth (after $40 \mathrm{hr}$ ) } \\
\hline & Sodium acetate & Yeast extract & $-\mathrm{M}$ & $+\mathrm{M}$ \\
\hline \multirow[t]{4}{*}{ Defined } & $2 \cdot 0$ & . & - & ++ \\
\hline & 0.4 & . & \pm & ++ \\
\hline & 0.08 & . & - & - \\
\hline & $\cdot$ & . & - & - \\
\hline \multirow[t]{5}{*}{ Defined } & . & $4 \cdot 0$ & +++ & . \\
\hline & . & $2 \cdot 0$ & +++ & + \\
\hline & . & $I \cdot O$ & +++ & - \\
\hline & . & 0.5 & + & . \\
\hline & . & 0.2 & \pm & . \\
\hline \multirow[t]{6}{*}{ Partly defined } & $5 \cdot 0$ & . & - & + \\
\hline & $2 \cdot 0$ & . & - & ++ \\
\hline & $\mathrm{I} \cdot \mathrm{O}$ & . & - & ++ \\
\hline & 0.4 & . & \pm & ++ \\
\hline & 0.1 & . & - & + \\
\hline & $\cdot$ & . & - & \pm \\
\hline \multirow[t]{5}{*}{ Partly defined } & $2 \cdot 0$ & $4 \cdot 0$ & \pm & $+t+$ \\
\hline & $2 \cdot 0$ & $2 \cdot 0$ & \pm & +++ \\
\hline & $2 \cdot 0$ & $I \cdot O$ & - & $+t+$ \\
\hline & $5 \cdot 0$ & $2 \cdot 0$ & - & • \\
\hline & $I \cdot O$ & $2 \cdot 0$ & ++ & . \\
\hline
\end{tabular}

Table 7. Numbers of colonies formed by Pediococcus cerevisiae 8081 and 8081 CRD in the presence of various additions to the medium

The colonies formed after incubation of plates for $\mathrm{I} 10 \mathrm{hr}$ at $37^{\circ}$ were counted as described in methods. The inoculum was a 20 hr culture in partly defined medium (containing methicillin in the case of $808 \mathrm{r}$ CRD), diluted to give about 200 colonies/plate. Medium: partly defined, without $\mathrm{Na}$ acetate. Additions as in Table 4.

Colonies $/ \mathrm{ml}$. of undiluted $20 \mathrm{hr}$ culture

\section{Medium in plates}

Medium $+\mathrm{Na}$ acetate (A)

A+methicillin

A+yeast extract

A + methicillin + yeast extract

Medium without $\mathrm{Na}$ acetate (B)

B + methicillin

B+ yeast extract

$\mathrm{B}+$ methicillin + yeast extract

$\begin{array}{cc}P . \text { cerevisiae } 8081 & \begin{array}{c}P \text {. cerevisiae } \\ 808 \mathrm{I} \mathrm{CRD}\end{array} \\ 3.4 \times 10^{8} & 2.3 \times 10^{3} \\ 0 & 4.4 \times 10^{8} \\ 3.8 \times 10^{8} & 2.0 \times 10^{4} \\ 0 & 5.3 \times 10^{8} \\ * 10^{9} & 4.2 \times 10^{2} \\ 1.7 \times 10^{2} & 0 \\ 3.1 \times 10^{8} & 1.8 \times 10^{8} \\ 0 & 5.1 \times 10^{8}\end{array}$

* The colonies were very small.

$\dagger$ The culture of $P$. cerevisiae $808 \mathrm{I}$ CRD gave a count of $3.6 \times 10^{8}$ particles $/ \mathrm{ml}$. in the counting chamber, under the phase-contrast microscope. 
Colony counts were also made on cultures of Pediococcus cerevisiae 808I CRD growing in liquid media of various compositions (Fig. $6 a-c$ ). Samples were removed from the cultures and suitable dilutions were plated on solid medium with and without methicillin. For $50 \mathrm{ml}$. of liquid culture, an inoculum of about $2 \times 10^{7}$ organisms was used, so that some methicillin-independent organisms (about 200/50 ml.) would be present initially. In medium containing sodium acetate (Fig. $6 a$ ) without methicillin, the number of viable methicillin-dependent organisms decreased fairly rapidly, whereas the number of methicillin-independent organisms increased by a factor of $10^{7}$, although their growth ceased when only slight turbidity was visible in the liquid culture. When methicillin was present, the growth of methicillin-independent organisms was very much diminished, but the methicillin-dependent organisms grew well.
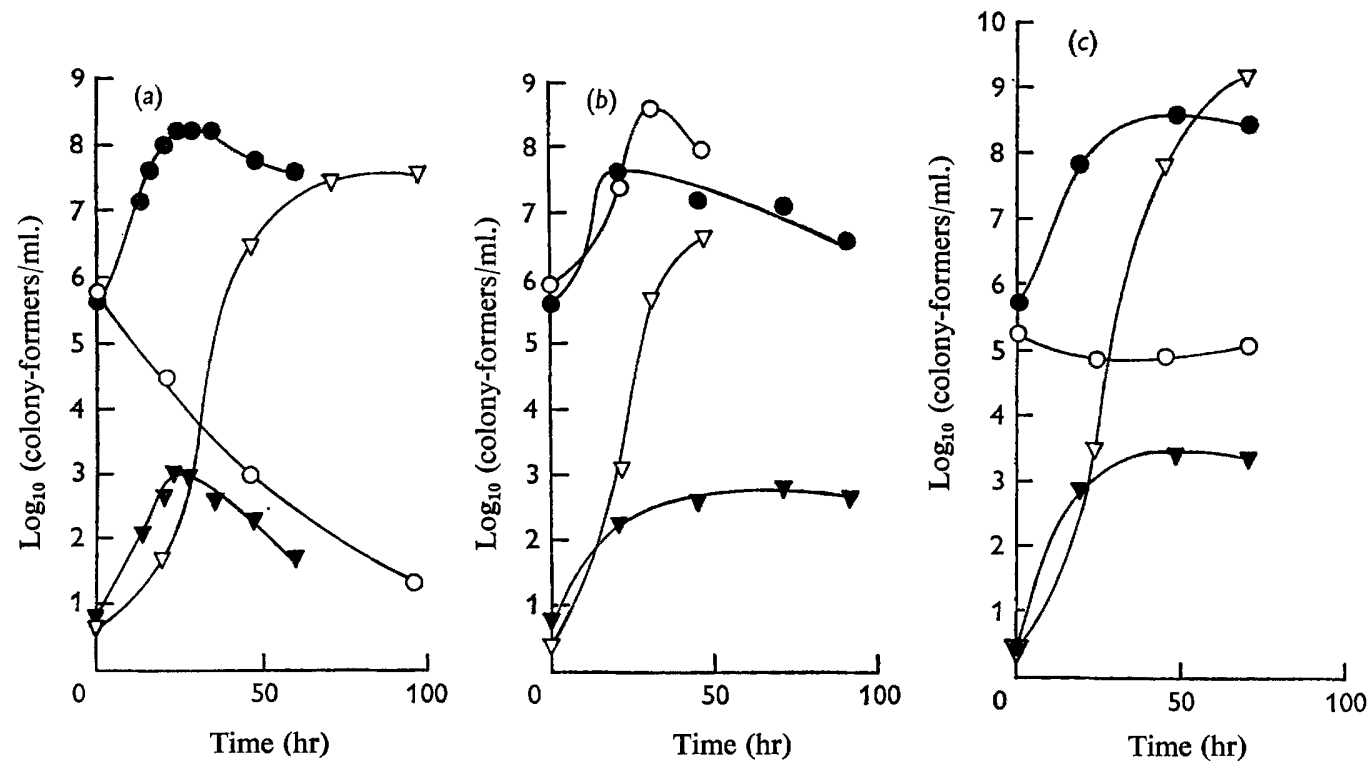

Fig. 6. Colony counts during growth of Pediococcus cerevisiae 808I CRD in liquid media of various compositions. (a) Partly defined medium (containing sodium acetate). (b) Medium without sodium acetate, containing yeast extract. (c) Medium containing sodium acetate and yeast extract. Medium ( $50 \mathrm{ml}$.) in $100 \mathrm{ml}$. flasks was inoculated with $0.1 \mathrm{ml}$. of an overnight culture of $P$. cerevisiae $8081 \mathrm{CRD}$ (from medium containing methicillin) and incubated at $37^{\circ}$. At intervals samples were removed for plating in Difco CF assay medium agar (+ leucovorin) with and without methicillin (100 $\mu \mathrm{g} . / \mathrm{ml}$.). 0 , Methicillin (100 $\mu \mathrm{g} . / \mathrm{ml}$.) in liquid medium; viable count in solid medium plus methicillin. $\nabla$, Methicillin in liquid medium; viable count in solid medium without methicillin. $O$, No methicillin in liquid medium; viable count in solid medium plus methicillin. $\nabla$, No methicillin in liquid medium; viable count in solid medium without methicillin.

Methicillin-dependent organisms grew in the absence of methicillin in medium without sodium acetate but containing yeast extract (Fig. 6b). In this medium, methicillin decreased rather than augmented growth of the methicillin-dependent organisms. Methicillin-independent organisms also grew in this medium, but only to a limited extent when methicillin was present.

In medium containing sodium acetate and yeast extract (Fig. 6c) without methicillin, the number of viable methicillin-dependent organisms remained virtually 
unaltered during the incubation, while the number of methicillin-independent organisms increased by a factor of $10^{9}$, and the liquid culture (after incubation for about $45 \mathrm{hr}$ ) became very turbid. The presence of methicillin in the liquid medium again led to growth of methicillin-dependent organisms, and diminished growth of methicillin-independent organisms.

\section{DISCUSSION}

In the present work only one attempt to develop resistant organisms was made with benzylpenicillin and one with methicillin. It is therefore not possible to say whether or not the production of a methicillin-requiring strain of Pediococcus cerevisiae was a very rare occurrence, although the fact that dependence became progressively more pronounced in several successive subcultures does suggest that the dependence was not the result of a single infrequent genetic event. Resistance to methicillin also increased by a number of small steps, which is in keeping with the common finding that resistance to penicillins (when not due to penicillinase production) develops only gradually. The failure to develop resistance to benzylpenicillin was not surprising because penicillin resistance does not generally occur with the streptococci (to which $P$. cerevisiae is fairly closely related). Since moderate resistance to methicillin was developed fairly readily and since the organisms were not appreciably crossresistant to other penicillins, it does seem that methicillin has some special effect of its own, as other studies have suggested already (Rogers \& Jeljaszewicz, I96 I Izaki, Matsuhashi \& Strominger, I966).

The methicillin-dependent strain was quite stable, in the sense that the strain was maintained through many subcultures in liquid medium containing methicillin (at a concentration inhibitory to the parent strain). Such a medium would suppress growth of non-resistant revertant organisms (whether or not methicillin-dependent) but would allow growth of resistant strains that had reverted to independence of methicillin. Presumably, if any such revertants did arise, they had no selective advantage over the methicillin-dependent organisms, since these were not overgrown. In spite of this ease of maintenance, about one cluster of organisms in every $10^{5}$ clusters was able to form a colony in the absence of methicillin, and these organisms seemed to be only partly reverted to the parent type, since they grew more slowly and much less heavily than did the parent organisms in a liquid culture.

The sample of methicillin used to develop the methicillin-dependent substrain was from an early batch, and was obtained before the drug was widely available. It seemed possible at the time that growth-promoting effect of the material used might have been due to impurities, but this explanation now seems most unlikely. Every batch of methicillin used has been active, and several other derivatives of 6-aminopenicillanic acid also showed growth-promoting activity. This activity was lost after hydrolysis with penicillinase which would not be expected to degrade an impurity (unless of very similar structure to a penicillin).

If it be accepted that the growth-promoting effect is due to the methicillin molecule itself, its role remains a problem. Methicillin (at 50-100 $\mu \mathrm{g} . / \mathrm{ml}$.) gave the most rapid and heavy growth of the dependent organisms; no other penicillin was as effective. Nonetheless, all the derivatives of 6-aminopenicillanic acid tested had some activity as growth factors, often at low concentrations. In every case except methicillin, the concentration at which a penicillin was active as a growth factor was about the same 
as the concentration at which the same penicillin was inhibitory to the parent strain $\left(C_{i}\right)$. This relationship rather strongly suggests that there is a close similarity between the way in which various penicillins cause inhibition of the parent strain or support growth of the penicillin-dependent substrain.

The usual inhibitory effect of a penicillin may be the result of acylation (by the $\beta$-lactam region of the antibiotic) of a sensitive enzyme (Strominger, Izaki, Matsuhashi \& Tipper, 1967): the values of $C_{i}$ might then be a relative measure of the reactivity of different penicillins in this process. The penicillin-dependent substrain might be supposed to overproduce the sensitive enzyme (with consequent unbalanced growth) and the presence of a penicillin might decrease the activity of the enzyme to a normal value. Alternatively, the dependent strain may produce a toxic metabolite which penicillin may remove by acylation. Either of these possibilities would be consistent with the failure of penicillins to act as growth factors after hydrolysis of the $\beta$-lactam ring.

The different values of $C_{i}$ might instead reflect the ease with which different penicillins were able to penetrate Pediococcus cerevisiae 808I and build up an intracellular inhibitory concentration, which might be about the same for the different penicillins. If this were so, then different penicillins might be broken down intracellularly in $P$. cerevisiae 808I CRD to yield rather similar amounts of some essential metabolite. That methicillin is broken down intracellularly in $P$. cerevisiae 808I CRD to provide nutrients seems unlikely; none of the possible fragments that have been tested (except 6aminopenicillanic acid) supported growth. This might have been because the fragments did not enter the organisms or were not attacked by enzymes, although these possibilities do not seem very likely.

In cases where two penicillins have been shown to cause an inhibitory effect at different concentrations (e.g. Rogers \& Mandelstam, 1962) it has been supposed that the two antibiotics differ in their reactivity with a sensitive site rather than in the extent to which they can enter the organisms. The sensitive site, because it is thought to be concerned with formation of the cell wall, would be expected to be near the surface of an organism, and so be accessible to penicillins in the medium.

At an intermediate stage of growth of the parent and the methicillin-dependent strains, material which inactivates methicillin was produced in the medium. This material is not an enzyme; preliminary studies indicated that it had a fairly low molecular weight. Formation of this material by the parent strain is not incompatible with the sensitivity to methicillin of organisms growing from a small inoculum, because the small population would be unable to inactivate the antibiotic before it had produced its toxic effect. Formation of the methicillin-destroying factor might even be disadvantageous to methicillin-dependent organisms by limiting their growth, through loss of methicillin from the medium.

The effects of sodium acetate, yeast extract and methicillin on growth of Pediococcus cerevisiae 808I CRD in partly defined medium, lead to the following conclusions. In yeast extract there is a factor (or factors) able to replace sodium acetate for growth of $P$. cerevisiae $808 \mathrm{I} \mathrm{CRD}$, and when this factor is used in place of acetate, methicillin is no longer needed for growth. Sodium acetate inhibits the response to the yeastextract factor, but methicillin is able to overcome this inhibition. Preliminary attempts to identify the yeast extract factor were unsuccessful. Several compounds were tested for ability to replace acetate for growth of $P$. cerevisiae $808 \mathrm{I}$ CRD in the presence or 
absence of methicillin, but none was found which resembled the factor in yeast extract. Lipoic acid, over a narrow range of concentrations, had a limited ability to replace acetate, but growth with lipoic acid was not heavy or rapid under any conditions.

The reason for the inhibitory effect of acetate on growth of Pediococcus cerevisiae 808I CRD (with yeast extract) in the absence of methicillin is not known. The effect may be indirect and could be the result of an interaction, during autoclaving, between acetate and other compounds in the medium. Acetate may be responsible also for the requirement for methicillin in the absence of yeast extract. Low concentrations of acetate allowed slight to moderate growth without methicillin, but when the usual concentration of acetate was present there was no growth unless methicillin was also added; then good growth could take place. In the present work a penicillin was needed to overcome an inhibitory effect of acetate, while in staphylococci penicillin overcame an inhibition by oleate (Jackson, I953), and in an L-form of Proteus mirabilis high concentrations of penicillin prevented the action of an inhibitor which was tentatively identified as formate (Altenburn, 196I).

The primary inhibitory action of penicillins is believed to be an interference with formation of the bacterial cell wall. It therefore seemed possible that a comparison of the cell walls of parent and methicillin-dependent strains of Pediococcus cerevisiae might give some clue to the reasons for methicillin-dependence. Some results of such a study are described in the following paper (White, 1967).

I thank Dr Elizabeth Work for her advice and encouragement through all stages of this work, and Miss Audrey Suffling for many valuable discussions and for technical assistance at the beginning of the work. Mrs Bridget Kelly and Mrs Hélène Theodoseou also gave excellent technical assistance. Thanks are due to the following persons, who have provided chemicals: Professor E. P. Abraham (University of Oxford); Mr F. R. Batchelor (Beecham Research Laboratories, Brockham Park, Betchworth, Surrey); Mr J. W. Lightbown (M.R.C., Mill Hill); Dr G. Popják (Shell Research Laboratories, Sittingbourne); Dr P. E. Reynolds (Sub-department of Chemical Microbiology, University of Cambridge); Dr D. F. Spooner (Boots Pure Drug Co. Ltd, Nottingham); Dr D. L. Swallow (I.C.I. Pharmaceuticals Division, Alderley Park, Cheshire); and the late Professor D. D. Woods (University of Oxford).

Permission to reproduce Fig. 4 (from Work, 1962) was kindly given by Messrs J. and A. Churchill Ltd, London.

\section{REFERENCES}

Abraham, E. P. (1955). Penicillinase. In Meth. Enzymol. 2, 120.

Altenburn, R. A. (1961). Critical factors influencing growth of L-forms of Proteus mirabilis. J. Bact. $81,586$.

ANDerson, W. F., Gorini, L. \& Breckenridge, L. (1965). Role of ribosomes in streptomycinactivated suppression. Proc. natn. Acad. Sci. U.S.A. 54, 1076.

Barber, M. (I953a). Penicillin-resistant and penicillin-dependent staphylococcal variants. J. gen. Microbiol. 8, I11.

Barber, M. (1953b). Antibiotic-resistant staphyloccal variants. Symp. Soc. gen. Microbiol. $3,235$.

GoRini, L. \& Kataja, E. (1964). Phenotypic repair by streptomycin of defective genotypes in $E$. coli. Proc. natn. Acad. Sci. U.S.A. 5I, 487 . 


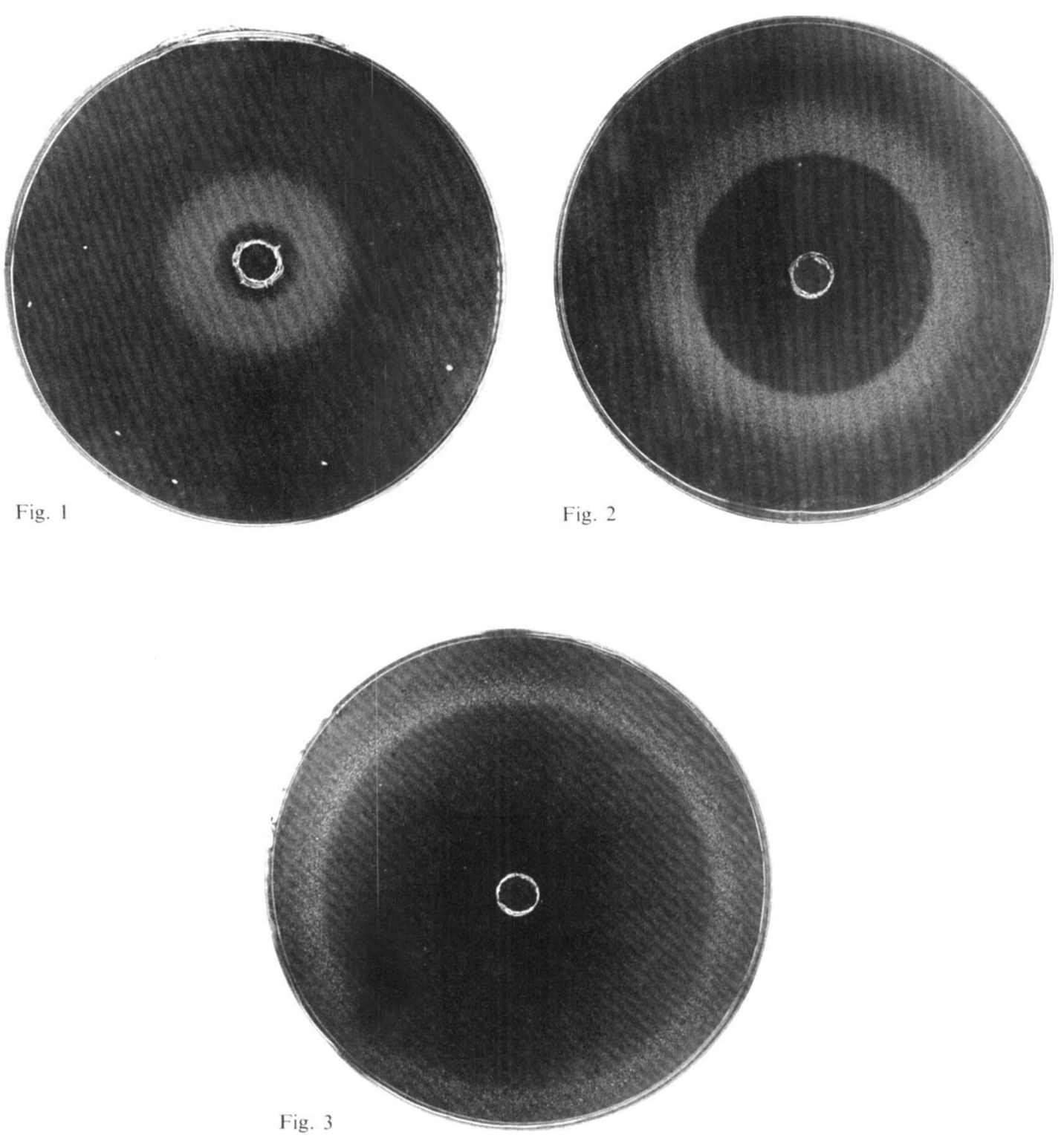
IZAKI, K., Matsuhashi, M. \& STrominger, J. L. (I966). Glycopeptide transpeptidase and D-alanine carboxypeptidase: penicillin-sensitive enzymatic reactions. Proc. natn. Acad. Sci. U.S.A. 55, 656.

JACKson, F. L. (1953). Discussion. Symp. Soc. gen. Microbiol. 3, 249.

Marshall, J. H. \& KelSey, J. C. (1960). A standard culture medium for general bacteriology. J. Hyg. Camb. 58, 367.

Reed, J. L., De BusK, B. G., Gunsalus, I. C. \& Hornberger, C. S. (Jr.) (I95I). Crystalline $\alpha$-lipoic acid: a catalytic agent associated with pyruvate dehydrogenase. Science, N.Y. II4, 93.

RoGERS, H. J. \& JELJASZEWICZ, J. (196I). Inhibition of biosynthesis of cell-wall mucopeptides by penicillins. Penicillin-sensitive and penicillin-resistant strains of Staphylococcus aureus. Biochem. J. 8I, 576.

Rogers, H. J. \& MANDELSTAM, J. (I962). Inhibition of cell-wall-mucopeptide formation in Escherichia coli by benzyl penicillin and 6-[D(-)- $\alpha$-aminophenylacetamido]penicillanic acid (ampicillin). Biochem. J. 84, 299.

Rolinson, G. N., Stevens, S., Batchelor, F. R., Cameron-Wood, J. \& Chain, E. B. (I960). Bacteriological studies on a new penicillin-BRL. I24I. Lancet, ii, 564 .

Sauberlich, H. E. \& BaumanN, C. A. (1948). A factor required for the growth of Leuconostoc citrovorum. J. biol. Chem. $\mathbf{1 7 6 , 1 6 5 .}$

SCHNTTZER, R. J. \& GRUNBERG, E. (1957). Drug Resistance of Microorganisms. New York: Academic Press Inc.

Strominger, J. L., Izaki, K., Matsuhashi, M. \& TipPer, D. J. (1967). Peptidoglycan transpeptidase and D-alanine carboxypeptidase: penicillin-sensitive enzymatic reactions. Fedn. Proc. $26,9$.

WhITE, P. J. (1962). A penicillin-dependent substrain of Pediococcus cerevisiae. Abstr. VIII Congr. int. Microbiol. Montreal, p. 75.

WhrTE, P. J. (1967). A comparison of the cell walls of Pediococcus cerevisiae and of a substrain that requires methicillin for growth. J. gen. Microbiol. 50, 107.

WhITE, P. J. \& NichOL, C. A. (1963). Effects of uracil and thymidine on the development of resistance to 5 -fluorouracil in Pediococcus cerevisiae. J. Bact. 85, 97.

WhITE, P. J. \& Woods, D. D. (1965). The synthesis of $p$-aminobenzoic acid and folic acid by staphylococci sensitive and resistant to sulphonamides. J. gen. Microbiol. 40, 243.

Work, E. (1962). Discussion in Resistance of Bacteria to the Penicillins. Ed. by A. V. S. de Reuck and M. P. Cameron, CIBA Foundation Study Group no. 13. p. 50. London: J. and A. Churchill Ltd.

\section{EXPLANATION OF PLATE}

Stimulation by methicillin or benzylpenicillin of growth of Pediococcus cerevisiae 8081 CRD in solid medium. Bottom layers ( $\mathrm{IO} \mathrm{ml}$.) were poured in Petri dishes from partly defined medium (at $43^{\circ}$ ) seeded with $0 . \mathrm{I}$ ml. of a $24 \mathrm{hr}$ culture of $P$. cerevisiae $808 \mathrm{I} \mathrm{CRD}$. A hole $(8 \mathrm{~mm}$. diam.) was cut out and was filled with $0.1 \mathrm{ml}$. of a solution of methicillin or benzylpenicillin in medium containing agar. Cover layers ( $30 \mathrm{ml}$. uninoculated medium) then were poured, and the plates were incubated at $37^{\circ}$. At the end of the incubation the holes were again cut out, so that their positions would show more clearly on photographs.

Fig. I. Methicillin ( $500 \mu \mathrm{g}$.) in centre well. Plate incubated for six days. The zone of confluent growth appeared after two days. Eight colonies of methicillin-independent organisms can be seen. These first appeared on the fourth day of incubation.

Fig. 2. Benzylpenicillin ( $25 \mu \mathrm{g}$.) in centre well. Plate incubated for 3 days.

Fig. 3. Benzylpenicillin (I25 $\mu$ g.) in centre well. Plate incubated for 3 days. 